\title{
Necessidades e expectativas dos usuários na educação a distância: estudo preliminar junto ao Programa de Pós-Graduação em Engenharia de Produção da Universidade Federal de Santa Catarina
}

Eliane Maria Stuart Garcez

Doutoranda em engenharia de produção. Professora da Universidade do Vale do Itajaí.

E-mail: garcez@newsite.com.br

\section{Gregório J. Varvakis Rados}

Doutor pela Universidade Loughborough. Professor do Departamento de Ciência da Informação e do Programa de Pós-Graduação em Engenharia de Produção da Universidade Federal de Santa Catarina. E-mail: grego@eps.ufsc.br

\section{Resumo}

Apresenta pesquisa que objetiva identificar necessidades e expectativas informacionais de usuários de bibliotecas acadêmicas realizada junto aos mestrandos e professores dos cursos a distância do Programa de Pós-Graduação em Engenharia de Produção da Universidade Federal de Santa Catarina, dando ênfase à qualidade em serviços. Os resultados mostram que os modelos de bibliotecas acadêmicas devem estar centrados na voz dos usuários, pois necessitam de informação para a obtenção de conhecimento, para atualização, produção de artigos científicos e dissertações. Também, esperam que as unidades informacionais disponibilizem produtos nos diversos suportes existentes, isto é, convencionais e digitais.

\section{Palavras-chave}

Necessidades de usuários; Expectativas de usuários; Educação a distância.

Users' needs and expectations in distance education: preliminary study within the Postgraduate Program in Engineering of Production of Federal University of Santa Catarina

\begin{abstract}
The aim of this study was to identify the informational necessities of academic library users (graduate students and professors of the distance education courses on Production Engineering Post Graduation Program of the Federal University of Santa Catarina), emphasizing the quality of the services provided. The results show that the academic library models need to be driven by the users voices, users that need to obtain knowledge through information, to produce scientific articles and assays, to be up to dated. They also expect that the Informational Units make the informational products available in many different ways, conventional and digital.
\end{abstract}

\section{Keywords}

Users needs; Users expectations; Distance education.

\section{INTRODUÇÃO}

Com a criação de novos ambientes, a inovação tecnológica possibilita um meio de acesso à aprendizagem a distância, por meio de novos ambientes para pessoas que se encontram dispersas geograficamente, evitando deslocamentos, além de favorecer o desenvolvimento de habilidades e competências cognitivas com autonomia, criatividade, autodisciplina, responsabilidade com a própria formação, construção do conhecimento e aprendizagem cooperativa.

Assim, os recursos informacionais devem estar disponibilizados de maneira que ofereçam, originalmente, bens e serviços* com valor agregado, capazes de satisfazer as necessidades e expectativas informacionais dos usuários dos cursos a distância e adaptados às novas racionalizações de tempo à localização física da informação, aos modos de aprendizagem individualizada e cooperativa.

Até os anos 80, houve grande preocupação com estudos de usuários presenciais. Porém, no final da década, houve uma paralisia temporária nessas investigações. $\mathrm{Na}$ década de 90, tais estudos começam a eclodir, propiciados pela explosão da gestão de qualidade total nas organizações. Desde então, começaram a ser intensificados os estudos de usuários a distância, e as bibliotecas acadêmicas passam a ter uma preocupação maior em fazer parcerias com os programas de educação a distância.

Em nível nacional, estão sendo realizados vários estudos de usuários a distância, tais como os de Castellani, Silva \& Brito (1997), Hypólito, Rosetto \& Do Couto (2000), Cuenca, Moraes e Fontes (2000) e Sadi \& Reis (2000). Em nível internacional, pode-se citar os trabalhos de Cutright \& Girrard (1993), MacDougall \& Britain (1993), Wielhorski (1994), Brinkley \& O'Farrel (1995), Erazo \& Derlin (1995), Shouse (1995), Wood \& Agogino (1996), Jagannathan (1996), Pitkow \& Kehoe (1996), Rodrigues (1996), Macauley (1997), Heron \& Dugan (1997) e Cooper et alii. (1998).

\footnotetext{
* Bem é entendido como algo físico, enquanto serviço significa trabalho feito por outro. Produto é o termo genérico para qualquer coisa que se produza, bem ou serviço.
} 
Conforme estes autores, estudos de usuários devem ser repetidos freqüentemente, porque eles tornam-se essenciais quando uma biblioteca passa por mudanças significativas e precisa avaliar como as expectativas dos usuários foram atendidas em relação aos serviços oferecidos, ou mesmo quando novos serviços são estudados e a opinião e o suporte do usuário são críticos no tocante às suas necessidades. Enfocam que é muito importante desenvolver estudos específicos na busca e no uso da informação como meio de verificar quais as variáveis influenciadoras deste comportamento, levando-se em consideração o contexto no qual estão inseridos, bem como as características pessoais e grupais dos usuários. Desta forma, as bibliotecas deverão dispor de resultados que poderão auxiliá-las a adequar seus bens e serviços às necessidades específicas de informações.

Conhecer as necessidades dos usuários é um princípio fundamental na administração a eles orientada. Ao transferir este princípio para o setor de informação, podese admitir uma significativa contribuição quando se adotam as técnicas de análise, pesquisa, segmentação de mercado e diagnóstico das necessidades do usuário, as quais são indispensáveis para a oferta de bens e serviços de qualidade, indo-se além de suas expectativas, mostrando qualidade superior à esperada. Neste sentido, é preciso adequar os recursos das unidades informacionais e da tecnologia da informação ao atendimento das necessidades e expectativas informacionais dos usuários, preocupandose em ouvi-los permanentemente, uma vez que suas necessidades de informações mudam constantemente, sendo necessário um processo de melhorias contínuas, de forma a perpetuar a organização ao longo do tempo.

Em suma, o que se pretende com este estudo é identificar, sob o ponto de vista dos usuários, quais suas necessidades e expectativas informacionais, para com isto auxiliar os gerenciadores de informação no planejamento de bibliotecas direcionadas aos cursos de educação a distância do Programa de Pós-Graduação em Engenharia de Produção/PRPGEP e, como resultado, disponibilizar bens e serviços informacionais com a qualidade esperada pelos usuários.

Esta pesquisa desenvolveu-se em três etapas. A primeira de investigação bibliográfica nas literaturas nacional e internacional para a elaboração de um quadro referencial. A segunda foi desenvolvida por meio da elaboração do instrumento de coleta de dados apresentados no apêndice I, na forma de um questionário a ser respondido por professores e mestrandos do PRPGEP, e da execução da pesquisa de campo (estudo de caso). E a terceira, de análise final, compreendeu a articulação dos dados coletados e do referencial teórico, por meio do seu confronto. A fim de obter melhor entendimento do tema, é muito importante a revisão da literatura, para deixar claro os conceitos de necessidades e expectativas que serão utilizados posteriormente para fundamentar a pesquisa de campo.

\section{CONCEITOS DE NECESSIDADES}

A necessidade é um estado no qual se percebe alguma privação. Maslow, apud Drumond (1995), desenvolveu uma hierarquia para as necessidades humanas, que foram categorizadas e ordenadas conforme a prioridade utilizada pelas pessoas, da mais à menos urgente: necessidades fisiológicas, de segurança, sociais, de estima e de autorealização. Logo, as necessidades fisiológicas, como alimento, roupa e abrigo, tendem a ter força mais intensa até serem satisfeitas, pois são básicas para a manutenção da vida. Para ele, quando estas necessidades são atendidas, outros níveis se tornam importantes. Neste caso, poderemos incluir a busca por informação quando ela passa a motivar e dominar o cotidiano dos usuários, já que é essencial para a sobrevivência nesse mundo tão competitivo.

Para Shera (1977, p. 9), a informação é o quinto fator imprescindível à sobrevivência física, pois cita em seu artigo que, em 1959, John Rader Platt, investigador da Universidade de Chicago, acrescentou "às tradicionais necessidades do homem - ar, água, alimentação e abrigo um quinto (grifo nosso) fator essencial à sobrevivência física, que é a necessidade de informação, de um fluxo de estímulos contínuo, novo, imprevisível, não redundante e surpreendente". Quem obtém a informação está mais apto à sobrevivência no mercado.

Kotler \& Amstrong (1993) também classifica as necessidades humanas em básicas, como alimento, água, vestuário e abrigo para sobreviver. Segundo ele, além disso, existe um forte desejo por recreação, educação, conhecimento e auto-realização, porque as pessoas satisfazem as suas necessidades com produtos, classificando-os em bens físicos, serviços e idéias.

Taylor* (1968, p. 178) criou uma estratégia de diagnóstico de necessidades, ou seja, "abordagem alternativa ou centrada no usuário, que é chamada de cinco filtros. São questionamentos que os bibliotecários devem fazer aos usuários de modo a determinar a busca por informação mais eficiente para satisfazer as necessidades de

* Taylor foi o precursor da abordagem alternativa ou centrada no usuário. 
informações. Os cinco filtros são os seguintes: assuntos de interesse, motivação, características pessoais dos usuários, relacionamento da pergunta com os arquivos e respostas antecipadas".

Lancaster apud Figueiredo (1974, p. 36) ressalta que as "necessidades têm várias conotações, em se tratando de informações, dentre elas, as necessidades de item apenas ou dado factual; necessidade de um ou mais documentos sobre um assunto, usualmente os mais recentes; necessidade de uma busca ampla, que recupere tanta informação quanto possível sobre um determinado assunto, em dado período".

Para Cole (1998), a base de uma boa pesquisa é uma clara definição de necessidades, ou seja, a pergunta na forma de uma frase, sentença ou parágrafo. Para desenvolver tal definição, o pesquisador precisa conhecer o objetivo e o conhecimento subjetivo sobre o tópico da pesquisa.

Kuhlthau (1994) fundamenta-se em Taylor (1968) para argumentar que os usuários, quando iniciam uma atividade específica de busca por informações, passam por vários estágios e que, durante cada estágio, devem completar uma subtarefa específica. Em um dos estágios, a subtarefa é reconhecer sua necessidade de informação; em outro, é formar um foco na informação; em um terceiro estágio, a subtarefa é coletar as informações relacionadas ao tópico focalizado. Por meio da identificação de uma diferente necessidade de informação em cada estágio, criou um esquema de classificação de necessidades que, na teoria, vai permanecer constante, através do tempo e de pessoa para pessoa, na busca de informação para um trabalho escolar, semelhante à definição de um problema.

Ferreira (1995) sugere que o termo necessidade de informação seja modificado para busca de informação, pois é preciso reconhecer que essa necessidade nasce do papel que o indivíduo desempenha na sua vida social.

Assim, determinar a necessidade de informação é muito importante, considerando que os usuários retratam os seus interesses reais. Neste estudo, como se trata de usuários a distância do Programa de Pós-Graduação, essas necessidades são mais explícitas, haja vista que iniciam no programa por um projeto de pesquisa e já estão familiarizados com os assuntos de interesse e sabem onde buscá-los. O que realmente pode acontecer durante o curso é essas necessidades serem modificadas de acordo com a realidade vivenciada. Desta forma, os gestores da informação devem estar preparados para flexibilizar bens e serviços para atender a expectativas dos usuários no decorrer do tempo.

\section{CONCEITOS DE EXPECTATIVAS}

Expectativas são, a priori, a probabilidade de alguma coisa ocorrer, elas refletem o desempenho antecipado (Figueiredo, 1994). Oliveira Júnior (1994) e Paim, Nehmy \& Guimarães (1996) enfocam que, para atender às expectativas do usuário, procurando inclusive superá-las, pode-se considerar cinco maneiras de gerenciar serviços: aprender a entender o que é valor para o usuário; especificar um sistema compatível com as expectativas do usuário; manter sob controle o processo de prestação de serviços; prover, de fatos curados, o sistema de informações; mensurar os resultados baseados nos anteriores, devendo considerá-los comparando-os entre o serviço esperado e o percebido. Os usuários costumam ter expectativas que podem ser consideradas bastante básicas. É de grande importância que exista um desempenho básico e que as promessas sejam cumpridas. Os usuários esperam um bem ou serviço de qualidade em um ambiente amigável e cortês.

De acordo com Cooper et alii. (1998, p. 3), "as expectativas são os padrões pelos quais a performance de um vendedor ou provedor de serviços deve ser julgada". Cada dimensão de expectativas vai, provavelmente, envolver dois níveis de serviços. O primeiro é o nível desejado ou o que o consumidor espera receber, uma mistura do que pode e deve ser. O segundo representa o nível adequado de serviço, aquele que o cliente ${ }^{*}$ acha aceitável. Para estes autores, as expectativas de serviços dos usuários são distribuídas nestes dois níveis, e os gerentes de informações com um bom entendimento das necessidades e expectativas de seus usuários vão ter maior sucesso em atendê-los. Todavia, o objetivo deve ser simplesmente superar o esperado, extrapolando suas expectativas, surpreendendo-os e deliciando-os. A administração das expectativas será eficiente, se forem mantidas as promessas de serviços feitas pela empresa, o serviço executado de forma confiável e se a comunicação com o cliente for eficaz.

Um elemento essencial é o esforço pedagógico por parte do pessoal da biblioteca, pois precisa ser honesto com os usuários, educando-os e informando-os a respeito do que esta pode ou não oferecer, quais serão os custos monetários (e outros) para o fornecimento dos produtos desejados. Esses elementos são imprescindíveis em um ambiente de educação a distância, onde usuários a distância podem apresentar menor lealdade pela instituição e estar dispostos a pesquisar em locais mais amigáveis.

\footnotetext{
* Cliente: refere-se a todos os alunos, professores e pesquisadores que poderão transforma-se em usuários das bibliotecas acadêmicas.
} 
Assim, o usuário avalia os serviços prestados por meio de suas expectativas, porque ele verifica se o provedor da informação conseguiu ou não satisfazê-lo, comparando o que espera com o que percebeu, isto é, como vê o produto, e se ele considera suas necessidades atendidas. Cabe ressaltar que ele não hesitará em trocar de produto, caso apareça um outro que lhe seja mais adequado (figura 1).

As bibliotecas devem ser continuamente revitalizadas pela voz de seus usuários, uma vez que essa dinâmica criativa e renovadora pode torná-la responsável pela satisfação dos mesmos, atendendo às necessidades emergentes de uma comunidade em constante evolução. Devem ser concebidas como um negócio, igual a qualquer outro, onde o lucro pode ser dimensionado pelo crescimento e valorização da unidade informacional, bem como pela satisfação das necessidades de informação de sua clientela.

Logo, a necessidade de informação é caracterizada pela busca de conhecimentos que preencham uma lacuna de informação, essenciais para o suporte às atividades de ensino, pesquisa e mesmo profissional. A expectativa sugere uma antecipação à demanda da clientela, pois se trata de um desejo consciente por informação acessível, uso fácil, relevante e bens e serviços necessários a esses propósitos, entregues em tempo hábil.

É preciso identificar as necessidades dos usuários, quais sejam: tema e motivação. Sabedor destas necessidades informacionais, o provedor de serviços, mediante pesquisas junto aos usuários, poderá projetar modelos de bibliotecas de acordo com suas expectativas, isto é, o que o usuário espera em termos de bens e serviços.

\section{METODOLOGIA}

Esta pesquisa é um estudo de caso, de cunho exploratório e de campo, pois tem por objetivo descrever comportamentos de fenômenos, definir e classificar fatos variáveis (Salomon, 1977). A amostragem utilizada foi a não-probabilística, acidental ou por acaso, porque é a possibilidade de se extrair um elemento do universo de forma totalmente aleatória e não especificada. Como toda a população recebeu o questionário para preenchimento, consideraram-se apenas os casos que foram aparecendo, até que a amostra atingisse determinado tamanho (Rudio, 1999, p. 63).

A população constitui-se de 700 mestrandos, sendo que a maioria está distribuída geograficamente em três estados (Minas Gerais, Paraná e Mato Grosso) e 23 professores de Florianópolis-SC. Da população de mestrandos, 89 responderam ao questionário, obtendo-se um percentual de $12,71 \%$. Dos 23 professores, sete responderam ao
FIGURA 1

Comparação entre as expectativas e a percepção do serviço

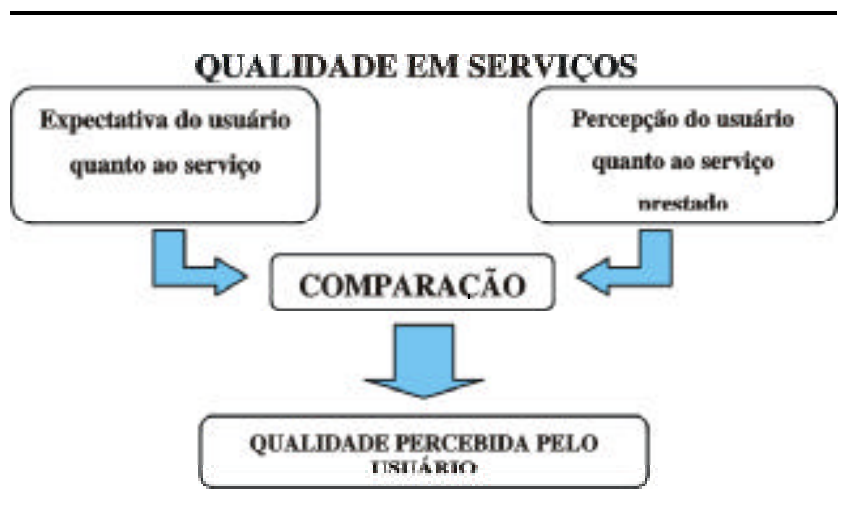

Fonte: adaptada de Gianesi \& Corrêa, 1996, p. 196.

questionário, obtendo-se um percentual de 30,43\%. Em termos estatísticos, a amostra possui $97 \%$ de confiança, $3 \%$ de significância e intervalo de aceitação de mais ou menos $10 \%$.

Como instrumento de coleta de dados, optou-se pelo uso do questionário on-line, disponibilizado através da URL: www.ufsc.br/pessoais/eliane/, e as respostas recebidas via e-mail. A escolha foi justificada pelos seguintes motivos: em decorrência de o público-alvo encontrar-se disperso geograficamente, o tamanho da população, que é numerosa, e a necessidade de se ter o registro das informações, haja vista a comprovação científica acerca dos resultados publicados e agilidade no envio e nas respostas. $\mathrm{O}$ instrumento foi previamente testado, sendo aplicado em duas turmas dos cursos presenciais. Algumas alterações foram realizadas, obtendo-se a sua forma final, com oito variáveis, a saber:

- Categorização da População Pesquisada (pergunta 1);

- Propósito de Busca por Informações (pergunta 2);

- Cobertura da Temática Informacional (perguntas 12 e 13);

- Acesso Informacional (perguntas 3, 4, 5, 8, 9, 10 e 11);

- Tipologia informacional (pergunta 6);

- Aquisição da Informação Acessada (pergunta 7);

- Tempo Tolerável na Obtenção da Informação (perguntas 14 e 15);

- Relevância em Treinamentos no Acesso a Bibliotecas Não Convencionais (perguntas 16 a 18). 
As variáveis foram ligadas a uma ou mais perguntas formuladas no questionário de coleta de dados (figura2), que, por sua vez, foram classificadas em três grupos: categorização, necessidades e expectativas de usuários (mais informações sobre a metodologia, ver trabalho na íntegranaU RL: www.eps.ufsc.br).

A seguir, serão apresentadas as interpretações e discussões relativas à aplicação do instrumento de coleta de dados.

\section{ANÁLISE E DISCUSSÃO DOS RESULTADOS}

C om os resultados obtidos junto à pesquisa de campo, verificou-se que tanto professores quanto mestrandos possuem necessidades informacionais, motivados pela atualização de seus conhecimentos, bem como para publicação de artigos técnicocientíficos, tendo, inclusive, resultado em um percentual de 60,3\% asoma dos dois itens (atual ização e artigos), o que é muito relevante, referindo-se a mestrandos. 0 bteve-se, como resultado isolado, o percentual de $35,3 \%$; já era esperado que os mestrandos estivessem necessitando de informação para dar suporte à sua dissertação. Q uanto aos professores, confirmaram-se resultados

FIGURA 3

Propósito de busca por informação

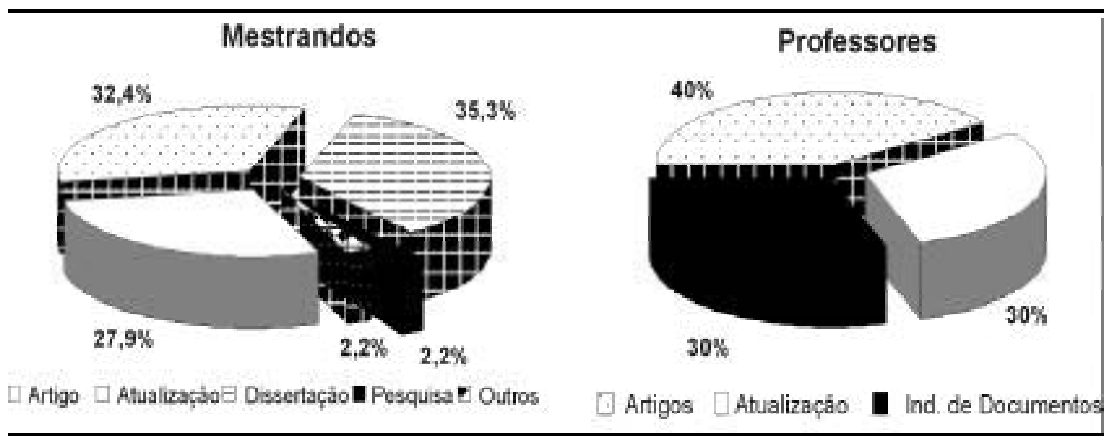
que parecem óbvios, como atualização do conhecimento $(30 \%)$, pesquisas para preparar aulas $(30,0 \%)$ e artigos técnico-científicos (40\%), apresentando-seum equilíbrio no percentual de cadaum deles (figura3).

Segundo Guinchat \& Menou (1994), a análise das necessidades, o conteúdo e o tipo de informação procurados e aceitos, do ponto de vista qualitativo e quantitativo, permitem definir os bens e serviços, como também o tipo de bibliotecas mais bem adaptadas a tais circunstâncias. Para Faibisoff \& Ely (1976), deve-se identificar a informação específica do que o usuário realmente necessita ou requer para o que está fazendo (propósito). Considerando-se que a produção do conhecimento inicia-se na busca de informações para a satisfação de uma necessidade, parte-se para 0 estabelecimento de relações, isto é, para o de que se necessitam determinadas informações e quais temas são importantes para obtê-las ( D udziak, G abriel \& Villela, 2000). Para autores como C utright \& G irrard (1993), M acD ougall \& Brittain (1993), Wielhorski (1994), Brinkley \& O 'F arrell (1995), Erazo \& D erlin (1995), Shouse (1995), Jagannathan (1996), R odrigues (1996), W ood (1996), H eron \& D ugan (1997) eM acauley (1997) $\&$ C ooper (1998), o ponto principal passa a ser com que
FIGURA 2

Classificação do instrumento de coleta de dados

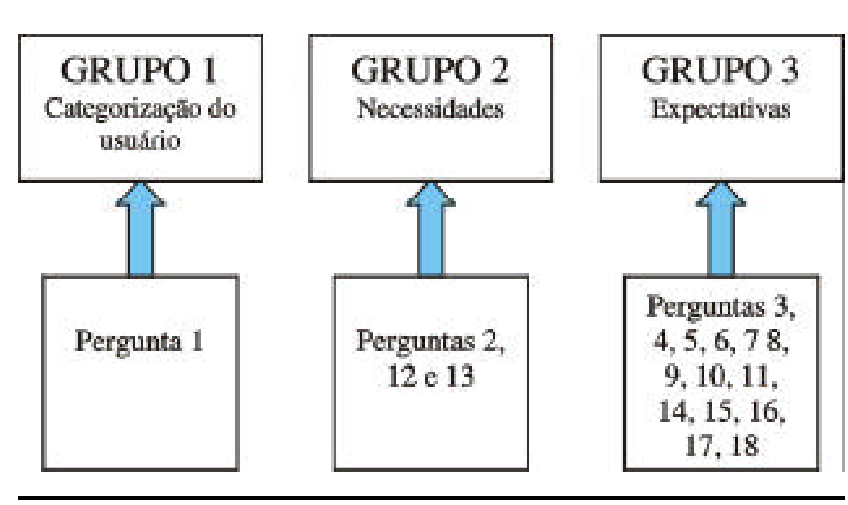

propósitos os sistemas são utilizados e como eles ajudam. U $m$ fator a ser considerado é que as necessidades de informação mudam no tempo, assim como o tipo de informação depende do indivíduo que a busca. A ssim, as unidades de informações devem ser flexíveis para permitir ao usuário adaptar o processo debusca de informação às suas necessidades, uma vez que essas são caracterizadas pela busca de conhecimentos que preencham umalacuna, imprescindíveis para o suporte às atividades de ensino, pesquisa e mesmo atividades profissionais.

Com relação aos temas de interesse dos mestrandos e professores, observou-se que a educação e a tecnologia apresentam o mesmo percentual 9,2\%, ea administração, $7,9 \%$; como terceiro tema mais citado, constatando-se que a área de mídia e conhecimento é a mais atrativa. O s temas diversos contaram com $47,4 \%$. Em relação aos professores, também houve um equilíbrio geral quanto aos temas deinteresse. I sto mostra queas preferências eas necessidades são diferentes para cada indivíduo. Faibisoff \& Ely (1976) sugerem queé preciso identificar o usuário em relação à sua disciplina ou meio ambiente (área), uma vez queas unidades de informações devem ser planejadas parafornecer a quantidade certa de informação no tempo 


\section{Eliane Maria Stuart Garcez / Gregório J. Varvakis Rados}

certo (distinção entre a necessidade e quantidade de informações disponibilizadas). De maneira semelhante, Lancaster (1979) enfoca que a utilidade de um documento é relativaàcombinação do assunto com os interesses do usuário. D essaforma, constatou-se que os temas são importantes para definir, no momento do planejamento, quais assuntos são relevantesà formação do acervo tanto virtual quanto convencional, para atender à necessidade informacional dos usuários, pois esta é formada por assunto e motivação.

O bservou-se que os meios mais utilizados para recuperar informações pelos mestrandos são as bibliotecas convencionais e as bases de dados em CD-ROM. Somando-se os dois meios, obtiveram-se $47,3 \%$ das preferências e as informações obtidas por meio de contatos pessoais foram 20,0\%. Em base de dados, alcançou-se um percentual de $29 \%, 0$ que, isoladamente, é muito significativo, pois demonstra a utilização de ferramentas naWeb. D estaforma, notou-sequeaconsulta local ainda é muito utilizada, no que se refere aos mestran dos. 0 s mesmos resultados foram obtidos em relação aos professores, pois o somatório daindicação de pesquisas em bibliotecas convencionais e em CD -RO M resultou em $43,5 \%$, vindo, em segundo lugar, os contatos pessoais eas bases dedados. $\mathrm{N}$ o entanto, também severifica que o acesso à base de dados (26,1\% ) é muito expressivo isoladamente (tabela 1) . C astellani, Silva \& Brito (1997) também observaram, em pesquisa realizada com alunos e professores daU SP, queas bibliotecas presenciais easfontes em CD -RO M são as maisutilizadas entreosalunos; jáentre osprofessores estão al nternet eCD -RO M.

M acauley (1995) constatou, em um estudo de necessidade de informação dos estudantes a distância de educação superior da U niversidade de D eakin, que os tipos tradicionais de serviços continuam sendo os mais requisitados eusados. Conforme Cooper etalii (1998), os estudantes de educação a distância são altamente motivados e familiarizados com as bibliotecas locais, e muitos deles não estão familiarizados com recursos eletrônicos. Figueiredo (1994) corrobora esses estudos quando enfocaquea acessibilidadeefacilidade do uso são os fatores mais determinantes paraa utilização ou não de um serviço de informação. Refere-se, neste sentido, ao uso fácil eà abrangênciaque o formato impresso apresenta, pois está em maior número que o formato eletrônico, bem como é acessível em bibliotecas convencionais, o quejáé uma prática arraigadano meio acadêmico. A acessibilidade é influenciada pela experiência pessoal, ou seja, quanto mais experiência no uso de um canal, mais ele se torna acessível para os usuários. Lancaster (1979) partilha das mesmas opiniões, já que, segundo esse autor, o sistema deve se adaptar aos hábitos dos usuários enão insistir que o usuário se adapte ao sistema.

Referindo-se aos meios mais utilizados para recuperar informações, em relação a bibliotecas virtuais, verificouse que a biblioteca da UFMG é a mais consultada, apresentando um percentual de $25,84 \%$ dos mestrandos. A inda no tocante a mestrandos, as bibliotecas locais mais visitadas foram a PU C-BH e a U N B-DF, as duas com $13,48 \%$ e as demais com $58,42 \%$. Referindo-se aos professores, em pesquisalocal, $57,14 \%$ utilizam aU FSC e virtualmentea mesmauniversidade apresenta $28,57 \%$ das preferências. 0 maior número de freqüência obtido ficou por conta dos usuários que não pesquisam em bibliotecas virtuais; mestrandos com 44,94\%; e professores com $57,14 \%$ (figura 4). Esteresultado deve-se, provavelmente, a aproximação físicatanto de alunos quanto deprofessores 
em relação às bibliotecas locais apontadas. Pode-se dizer que os mestrandos e professores ainda utilizam muito pouco as bibliotecas virtuais, no entanto utilizam freqüentemente bibliotecas convencionais e ferramentas de buscas quase que regularmente. Levando-se em conta esta constatação, considera-se que este tipo de usuário a distancia é experiente no acesso e na busca por informação. Em se tratando de professores, tais comportamentos fazem parte de sua vida profissional. A falta de acesso a bibliotecas virtuais, tanto por parte de professores como de mestrandos, pode ser motivada por fatores como a falta de intermediação no seu uso, o relacionamento usual com as bibliotecas convencionais (por terem maior abrangência de assuntos em seus acervos), ou mesmo porque a informação disponibilizada nos sites das bibliotecas virtuais não seja adequada às reais necessidades informacionais deste tipo de usuário.

Os mesmos resultados foram obtidos em pesquisas realizadas por Macauley (1995) na Universidade de Deakin, que opera a maioria dos serviços bibliotecários para os estudantes a distância. Os estudos mostram que, em cursos de pós-graduação, os estudantes fazem menos uso da biblioteca virtual do que seria de se esperar. Sadi \& Reis (2000) relatam que, na literatura sobre educação a distância, foram encontradas poucas referências sobre o uso de bibliotecas ou recursos por elas disponibilizados para estudantes a distância. Existe pouco reconhecimento do papel das bibliotecas ou nenhum uso. Porém, contraditoriamente, em um estudo feito nas home pages de 76 bibliotecas universitárias brasileiras, ficou constatado que as bibliotecas nacionais e internacionais são as mais conectadas, segundo Bertholino, Pinto \& Inoue (2000 p. 11). Cole (1998), em estudos de performance de sistemas, observou que os tipos tradicionais de serviços continuam sendo os mais requisitados e usados. Assim mesmo, havia uma demanda definida por acesso via discagem por bancos de dados eletrônicos, catálogos de bibliotecas e Internet. Rusch-Feja (1999) corrobora estas pesquisas quando diz que a biblioteca híbrida é a solução para as necessidades informacionais dos usuários, pois seu acervo deve integrar acesso a diferentes tecnologias, por meio de diferentes mídias, dessa forma, fornecendo apoio à qualidade da educação.

Quanto às ferramentas de busca, os mestrandos têm preferências pelo Altavista (34,4\%), Yahoo (30,3\%) e Cadê $(15,9 \%)$, sendo que este último foi detectado na opção semi-aberta de uma das perguntas, o que pressupõe que a escolha deve ter sido feita por ser uma ferramenta que melhor atende às necessidades informacionais dos usuários. Já os professores optaram pelas mesmas ferramentas preferidas pelos mestrandos, destacando-se, como primeira opção, o Altavista, com 38,9\%, provavelmente por ser uma ferramenta mais completa, mais bem estruturada, mais difundida e por possuir maior abrangência de informações. Tais dados mostram que os usuários possuem familiaridade no acesso à informação através de ferramentas disponibilizadas na Web, pois uma possível explicação é que a maioria dos pesquisadores utiliza a Internet com a finalidade de pesquisa e que, de uma maneira geral, a maioria tem experiência com ferramentas de busca. Zhou (1994) constatou, em outros estudos, que os usuários utilizam os serviços na Internet que melhor atendam a suas necessidades e que não ofereçam apenas a localização física. Esta constatação foi confirmada em pesquisas realizadas pela Association of Research Libraries - ARL (Lancaster apud Hypólito et alii, 2000). Segundo Pitcow \& Kehoe (1996), em pesquisas conduzidas pelo Instituto Georgia de Tecnologia, 51,8\% da amostra de usuários que pesquisam na Web o fazem para fins acadêmicos, perdendo somente como primeira opção para simplesmente navegar e entretenimento. Isto, de uma forma ou de outra, auxilia na obtenção dos resultados observados nesta pesquisa, pois os usuários são ligados aos cursos a distância da UFSC e estão preocupados com a produção de conhecimentos.

Também se verificou que os artigos de periódicos e os livros são os tipos de materiais mais utilizados no meio acadêmico, seguindo-se de anais de congressos, resultando em um somatório de 52,4\%, em oposição às fontes eletrônicas, que obtiveram um percentual de 14,8\% isoladamente (tabela 2, a seguir). O mesmo se constatou em relação aos professores. A diferença está em que os professores utilizam mais os anais de congresso no formato impresso. Tais resultados confirmam a grande utilização do meio impresso e a demanda por documentos mais atualizados. Estudos de Sousa (1990), do Instituto de Pesquisas Energéticas e Nucleares (IPEN), mediante uso e não usos de canais formais e informais de informação, verificaram que pesquisadores consideram os livros como fontes mais usadas, seguindo-se, na ordem decrescente de importância, os artigos de periódicos. Sousa (1990) analisou o comportamento dos docentes, pesquisadores da área de tecnologia de alimentos da Universidade Federal de Londrina, e obteve os seguintes resultados: artigos de periódicos livros, abstracts, índices e arquivos pessoais como produtos mais utilizados. Neste sentido, notou-se, por meio da literatura, que, em estudos anteriores à década de 80 , os resultados obtidos eram os mesmos apresentados nesta pesquisa. Mostafa (1984) levanta um ponto relevante para esta pesquisa, ou seja, que as bibliotecas apresentam aos usuários o produto pronto, acabado, ignorando as preferências da clientela, sem se preocuparem em adaptar estes produtos às suas necessidades. 
Na comunicação informal, constatouse que o e-mail é o mais utilizado entre os mestrandos para a obtenção da informação, com $24,9 \%$ das preferências, seguindo-se do uso dos contatos pessoais, com $22,6 \%$, e fóruns eletrônicos, com 14,6\%. Foi verificado que o correio eletrônico vem se destacando como o meio mais utilizado na preferência dos usuários, em virtude de remeter a questão no momento da necessidade da informação. Pressupõe-se que, além do acesso rápido e especializado à informação, existe a facilidade da nãoobrigatoriedade da presença física. Com relação aos professores, os resultados obtidos foram praticamente os mesmos, contatos interpessoais $(35,0 \%)$, e-mail $(30,0 \%)$, e telefone $(25,0 \%)$ (tabela 3$)$.

Para Figueiredo (1994), a grande utilização dos colégios invisíveis é considerada mais importante do que os canais formais para satisfazer muitos tipos de necessidades de informação. As conversas entre cientistas propiciam trocas de informações com os mesmos interesses e aprovação dos pares, tão importante nas ciências. E é através da comunicação via correio eletrônico, chats, listas de discussões e fóruns eletrônicos que isto pode se concretizar, o que já faz parte da realidade atual, referindo-se à disseminação do e-mail. De acordo com Bertholino, Pinto \& Inoue (2000, p. 13), "o e-mail é o principal canal de comunicação entre as informações disponibilizadas e a biblioteca". Hypólito et alii (2000, p. 6) destacam que, em pesquisa conduzida pela State University of New York at Buffalo, foi verificado que o correio eletrônico vem se destacando como o meio mais utilizado na preferência dos usuários, em virtude de remeter a questão no momento da necessidade da informação.

TABELA 2

TABELA 3

FIGURA 5
Tipos de bens mais pesquisados em bibliotecas

\begin{tabular}{lcccc}
\hline \multirow{2}{*}{ BENS } & \multicolumn{2}{c}{ MESTRANDOS } & \multicolumn{2}{c}{ PROFESSORES } \\
& Freqüência & Percentual (\%) & Freqüência & Percentual (\%) \\
Anais & 13,17 & 14,8 & 1,59 & 22,6 \\
Apostilas & 12,28 & 13,8 & 0,45 & 6,5 \\
Artigos & 16,64 & 18,7 & 1,35 & 9,4 \\
Fontes eletrônicas & 13,17 & 14,8 & 1,13 & 16,1 \\
Livros & 16,82 & 18,9 & 1,13 & 16,1 \\
Monografias & 15,75 & 17,7 & 1,13 & 16,1 \\
Outros & 1,5 & $1, .3$ & 0,22 & 3,2 \\
TOTAL & 89 & 100,00 & 7 & 100,00 \\
\hline
\end{tabular}

Obtenção da informação entre pesquisadores

\begin{tabular}{lcccc}
\hline $\begin{array}{l}\text { COMUNICAÇÃO } \\
\text { INFORMAL }\end{array}$ & \multicolumn{2}{c}{ MESTRANDOS } & \multicolumn{2}{c}{ PROFESSORES } \\
& Freqüência & Percentual (\%) & Freqüência & Percentual (\%) \\
& & & & \\
Contato pessoal & 20,0 & 22,6 & 2,45 & 35,0 \\
E-mail & 22,0 & 24,9 & 2,10 & 30,0 \\
Fax & 11,0 & 11,8 & - & - \\
Fórum eletrônico & 13,0 & 14,6 & 0,35 & - \\
Lista de discussão & 5,0 & 5,4 & 0,35 & - \\
Telefone & 18,0 & 20,7 & 1,75 & 25,0 \\
TOTAL & 89 & 100 & 7 & 100 \\
\hline
\end{tabular}

Participação em fóruns eletrônicos

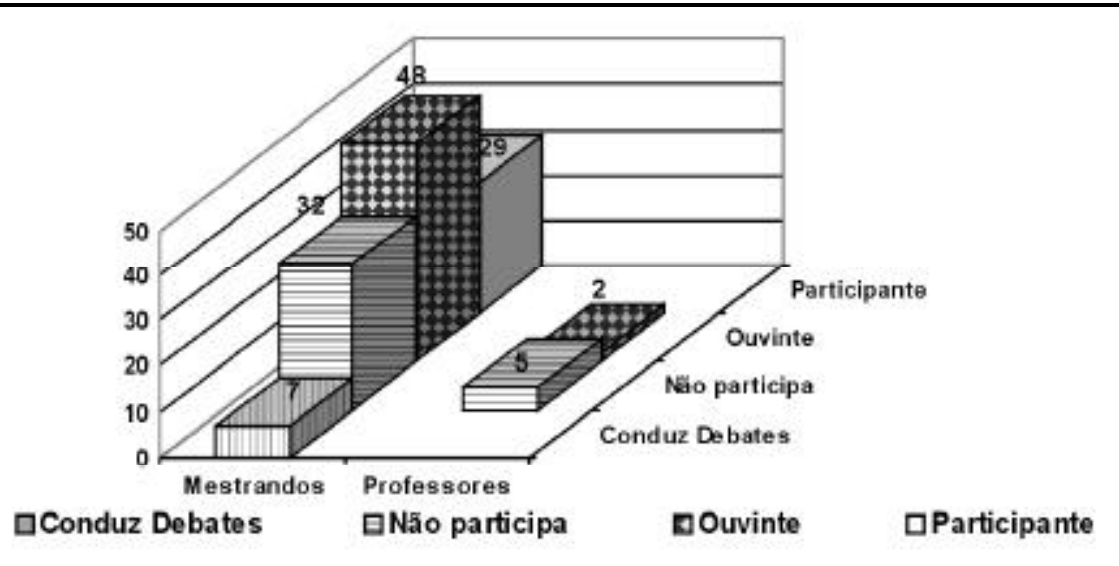

Com relação à participação de usuários remotos em fóruns eletrônicos, observou-se que esta ainda é muito pequena; referindo-se a amostra de 89 mestrandos, 32 (números absolutos) não participam. E, de uma amostra de sete professores, cinco não participam, como demonstrado na figura 5. Zhou (1994) verificou, em estudos obtidos com 
acadêmicos americanos da área de ciência da informação, resultados altamente positivos, o que não corrobora estes resultados. Pressupõe-se queesses acadêmicos americanos contam com a orientação curricular voltada para estes aspectos, o que facilita a disseminação do uso de tais mecanismos de comunicação. M acauley (1997) acha importante a utilização destes mecanismos de relações interpessoais, pois diminui o isolamento, principalmente em setratando de estudantes a distância. $\mathrm{N}$ o que se refere a professores, constatou-seque, em suamaioria, conduzem debates: dos sete pesquisados, cinco participam ativamente nacondução destes, o que já era esperado em decorrência desuas funções.

Q uanto a listas de discussão, verificou-se um percentual de não-participação de 45,5\% em relação aos professores e 75,8 em relação aos mestrandos ( tabelas 4 e 5), o que sugere a necessidade de intermediação por parte dos bibliotecários para agilizar este meio informal. Zhou (1994), em pesquisa com estudantes americanos da área de informação em nível de mestrado edoutorado, obteve um percentual relevante deusuários queutilizam o referido serviço, o quenão corrobora o constatado nesta pesquisa, pressupondo-seos mesmos motivos com relação aosfóruns eletrônicos; a população pesquisada é de estudantes da área de ciência da informação que já estão familiarizados com tais ferramentas. $\mathrm{H}$ ipólito et alii (2000, p. 549) auxiliam na comprovação deste pressuposto, pois observaram que os profissionais da área de informação figuraram como os mais antigos usuários de listas de discussões e que as listas como ISWorld e I nfoSys são recebidas por milhares de pesquisadores e estudantes da área de ciência da informação.

A aquisição da informação acessada demonstra mais uma vez que o meio impresso continua sendo muito utilizado, pois foram obtidos, com relação aos professores, no somatório C O MU T eempréstimo, 53,4\%. Porém, nota-sequea aquisição de informações por download, com $46,7 \%$, sobrepõe-se às outras duas isoladamente. Com isto, conclui-se queo meio eletrônico éo formato que está sendo mais utilizado no meio acadêmico, pelafacilidade de acesso e pelo menor custo (figura 6). L ancaster (1979) corrobora esta constatação, quando afirma que deve haver um acompanhamento ou a possibilidade de o sistema de informação propiciar acessibilidade ao documento, isto é,

\section{FIGURA 6}

TABELA 4

Participação em listas de discussão - Professores

\begin{tabular}{lcc}
\hline PROFESSO RES & Freqüência & Percentual (\%) \\
DEOS & 1 & 9,1 \\
DLDC & 1 & 9,1 \\
IAS & 1 & 9,1 \\
IBS & 1 & 9,1 \\
IFETS & 1 & 9,1 \\
UNU & 1 & 9,1 \\
N ão participa & 5 & 45,5 \\
Tota & 11 & 100,00 \\
\hline
\end{tabular}

TABELA 5

Participação em listas de discussão - Mestrandos

\begin{tabular}{lcc}
\hline MESTRAN DOS & Freqüência & Percentual (\%) \\
Bluemountain & 1 & 1,1 \\
CEV & 1 & 1,1 \\
Ducere & 1 & 1,1 \\
Edutecnet & 4 & 4,4 \\
Filhosdorei & 1 & 1,1 \\
Intermanag & 1 & 1,1 \\
Internetwork & 1 & 1,1 \\
Izabela5 & 1 & 1,1 \\
N etwaorking & 1 & 1,1 \\
Pontodeencontro & 1 & 1,1 \\
UECE & 1 & 1,1 \\
UNB & 1 & 1,1 \\
U N ICAM P & 1 & 1,1 \\
Wwebtrans & 1 & 1,1 \\
Yahoo & 1 & 1,1 \\
Zzz & 1 & 1,1 \\
N ão participa & 69 & 75,8 \\
ProgramaREU N E & 1 & 1,1 \\
Várias & 2 & 2,2 \\
Total & 91 & 100,00 \\
\hline
\end{tabular}

Aquisição da informação

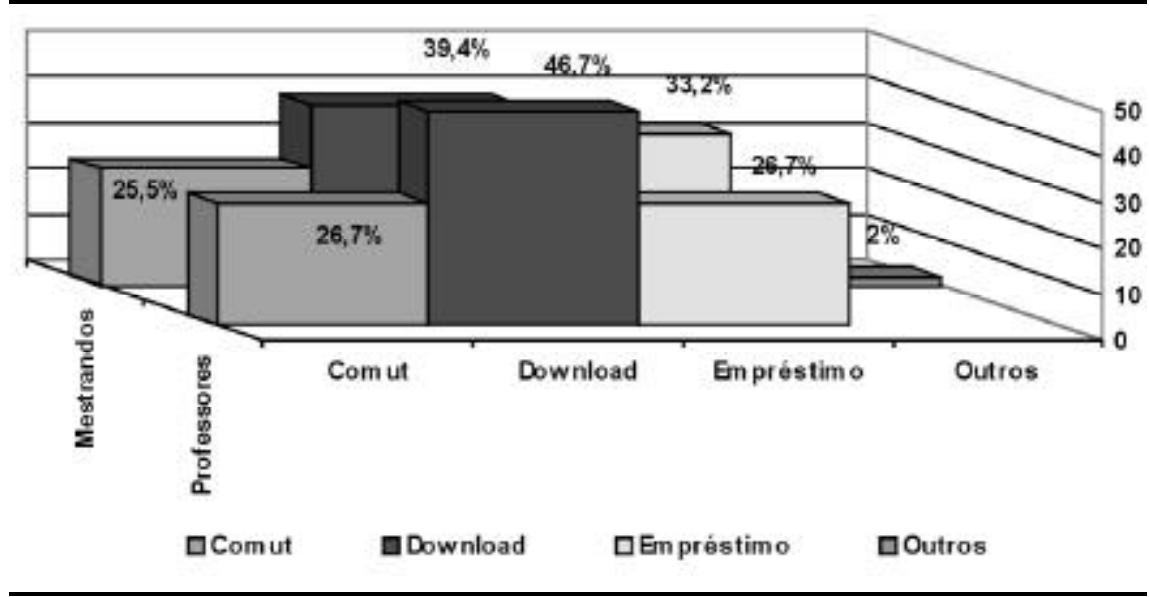


obter a cópia desejada, e não somente a referência bibliográfica, deixando ao usuário o problema da localização do documento. C hagas et alii (2000, p. 12) indicam queas "frustrações podem acontecer, quando, após o levantamento das referências, seja numa base de dados ou catálogo, não sepodeobter a obra por motivos diversos". Em uma pesquisa realizada por Sadi \& Reis (2000), percebeu-se que as bibliotecas americanas dispõem de empréstimos automatizados, que podem ser impressosou sal vos em discos, via solicitação por e-mail ou formulário eletrônico. Essas bibliotecas também podem indicar fornecedores de documentos comerciais, que enviam os documentos aos usuários, por e-mail ou fac-símile, para agilizar a posse da informação. Segundo estas mesmas autoras, no Brasil, as bibliotecas estão partindo para este caminho, iniciando com a disponibilização de periódicos eletrônicos. Tanto as bibliotecas norte-americanas quanto as brasileiras utilizam o correio convencional para 0 empréstimo de material impresso, principalmente entre elas. E o meio mais usado é a comutação bibliográfica (utilizando o softwareA riel).

Verificou-se também que os usuários, tanto professores quanto alunos, toleram muito pouco, ou seja, no máximo três dias, para a obtenção de um documento via e-mail, obtendo-se um percentual de $88,8 \%$ para mestrandos e $71,4 \%$ para professores. C om relação ao recebimento de documentos via correio, os usuários toleram no máximo sete dias de prazo paraa obtenção de um documento, pois se obteve um percentual de $80,9 \%$ para mestrandos e $57,1 \%$ para professores.. D essa forma, conclui-se que facilitar o acesso à informação não é suficiente, épreciso disponibilizar o documento o mais rapidamente possível. Cooper et alii (1998, p. 2) relatam que os usuários acadêmicos tendem a dar importância à confiabilidade eà responsabilidade. A ssim sendo, os usuários esperam 0 máximo etoleram o mínimo com relação à confiabilidade do serviço, eisto adquire ainda maior importância para os usuários a distância. Segundo Ramos (1999), os bibliotecários ainda não se conscientizaram da importância do fator tempo na obtenção da informação pelos usuários, principalmente nos dias de hoje, quando se apresenta uma realidade totalmente voltada para a competitividade e qualidade dos serviços buscados. $\mathrm{N} O$ contexto atual, não se admite mais a falta de tecnologia para agilizar o processo de recuperação e o acesso à informação, ondequer queela esteja. C onforme $O$ berhofer (1983), na percepção do usuário, a acessibilidade pode ser avaliada em termos de custos, que podem ser medidos em duas dimensões diferentes: custo em termos de tempo gasto corresponde ao tempo gasto pelo usuário na busca de informações, identificação e localização do item procurado; custo em termos do atraso experimentado está relacionado à distribuição do tempo empregado, tais como reservas, empréstimo entre bibliotecas, prazo de retenção etc., que compõe o tempo de espera para a obtenção do documento. Roberts (1973) e Lancaster (1974) \& Wood (1971) recomendam que o tempo de resposta éfator importanteda ef etividade. $N$ ão ésuficiente que a biblioteca satisfaça a demanda de seus usuários; é necessário que o faça em tempo útil, pois, quanto mais fácil o uso, melhor parao usuário, queagesempredeacordo com a lei do menor esforço. $\mathrm{N}$ ão é suficiente que a bibliotecasatisfaçaademanda de seus usuários, énecessário que a posse do documento seja efetuada no menor tempo possível.

O bservou-sequea maioria dos mestrandos (59,6\%) jáfoi instruídano uso de bibliotecas virtuais; em contrapartida, os professores, em sua maioria, não receberam estetipo de treinamento $(57,1 \%)$. Porém, as duas categorias, através da realidade vivenciada, acham muito importante esta prática. Também se verificou que os usuários sabem da importância dos treinamentos como ferramenta de ajuda imprescindível ao processo de busca por informações. E constatou-se que, em sua maioria, os usuários utilizam recursos da Internet, já foram treinados no uso de bibliotecas tanto convencionais, quanto não convencionaise possuem experiênciano acesso enabusca por informação, comprovando, desta forma, a val idação detais instrumentos. Segundo C ooper et alii (1998), os usuários queresidem próximo ao campusde universidades estão mais motivados, possuem experiências significativas com pesquisa bibliotecária e familiaridade com recursos eletrônicos, demonstrando um sucesso bastante al to no uso detecnologia da informação. Pressupõe-se, com isto, que os professores são usuários experientes e já foram treinados pelos $C$ entros del nformações. $N$ este sentido, também, pode-sefazer uma analogia com os mestrandos do PRPGEP, uma vez que os mesmos são usuários a distância, encontram-se próximos às universidades locais ou possuem acesso a elas. Segundo Ramos (1999), a formulação eficaz da estratégia de busca exige conhecimento do assunto, das bases de dados e da bibliografia; logo, deve ser realizada pelo clientetreinado ou pode contar com o auxílio do bibliotecário e pelo solicitante da busca. K uhlthau (1994) observou que, a cada avanço tecnológico, a educação de usuários dos serviços deinformações torna-se mais importante. C rescetambém a necessidade de adequação dos sistemas a seus usuários, de maneira a incorporar a dinâmica da construção do conhecimento. As novas ferramentas de busca da informação têm propiciado a agilização no processo ao acesso à informação; por outro lado, não se sabe ao certo 
como estes serviços estão sendo oferecidos e, muito menos, como estão sendo absorvidos (Linguanotto et alii, 2000).

Como as bibliotecas acadêmicas dão suporte ao ensino a distância, estas devem repensar sua missão de serviços, uma vez que os usuários a distância têm suas únicas e próprias características. Portanto, como resultado da pesquisa enfocam-se os mais relevantes, aos quais os gerenciadores de serviços devem atentar, que são os seguintes: antecipar as expectativas de seus usuários, incluindo serviços mais personalizados que os normalmente oferecidos; apoiá-los com informações em formatos convencionais (informação mais democrática e mais abrangente) e não convencionais (a utilização de documentos eletrônicos, que está se intensificando cada vez mais, pois propicia a posse imediata do documento e um menor custo em sua aquisição); procurar consórcios com bibliotecas próximas de onde se encontram os alunos a distância, dar-lhes auxílio técnico para navegação na Web e acesso rápido, confiável e seguro às redes da Instituição; serviços de orientação, principalmente no uso de equipamentos e mídia não impressa; entrega rápida de documentos, tais como transmissão eletrônica. Na prática, para responder às necessidades dos usuários, tais unidades informacionais podem desenvolver um tipo ou um misto destas atividades, ou mesmo desenvolver produtos ou serviços sofisticados que ultrapassem estas classificações.

\section{CONCLUSÕES FINAIS}

O estudo de caso caracterizou as expectativas e necessidades dos mestrandos e professores do PRPGEP, uma vez que estas são formadas pela motivação (o que faz com que os usuários busquem informações) e o assunto de seu interesse. Quanto às expectativas, elas refletem o que os usuários esperam que as unidades informacionais lhes ofereçam em termos de produtos informacionais (bens e serviços). E para que tais exigências sejam atendidas, é necessário que as bibliotecas atinjam seu principal objetivo: conhecer seus usuários. Desta forma, um produto que não esteja no nível daquilo que o usuário deseja o afastará definitivamente, fazendo com que o provedor de serviço não tenha uma segunda chance de fazê-lo, pois este poderá procurar outros serviços mais amigáveis, que atendam às especificações necessárias à sua lacuna de informação. Por isso, é preciso ir mais adiante, fornecendolhe o inesperado, para satisfazê-lo plenamente, em vez de simplesmente satisfazê-lo.
Como as bibliotecas acadêmicas dão suporte ao ensino a distância, estas devem repensar sua missão de serviços, pois, além de atender aos usuários presenciais, terão de atender os usuários a distância, com suas únicas e próprias características. Portanto, os bens e serviços bibliotecários devem constar no planejamento dos cursos a distância e estar disponíveis de maneira compatível com as necessidades dos seus usuários.

Nota-se que estudos de usuários a distância ainda são muito reduzidos no Brasil e existem muitas questões que merecem respostas, pois esses conhecimentos mais estreitos com os usuários irão auxiliar os gerenciadores de informações a melhor atender às necessidades deste novo nicho de mercado.

Por ser este um estudo de caso, seus resultados são limitados a este estudo. Porém, recomenda-se que essa pesquisa seja realizada em outras instituições de AED e que este estudo seja expandido em duas direções: que a amostra seja ampliada para uma nova pesquisa e que sofra um maior tempo de exposição.

Artigo aceito para publicação em 31-10-2001.

\section{REFERÊNCIAS BIBLIOGRÁFICAS}

BERTHOLINO, M.L.F.; PINTO, I.T.R.; INOUE, M.T.M. A Web como canal de divulgação de serviços e produtos de bibliotecas universitárias: análise do conteúdo de home pages. In: SEMINÁRIO DE BIBLIOTECAS UNIVERSITÁRIAS, 11, 2000, Florianópolis. Anais.... Florianópolis : UFSC, 2000.

BRINKLEY, M.; O'FARRELL, J. Delivery of library services to distance education students: the BIBDEL research project at Dublin city university library. Electr. Libr., v. 13, n. 6, p. 539-546, Dec. 1995.

CASTELLANI, M.R.; SILVA, S. M. da.; BRITO, M.J. de. Redes de comunicação eletrônica (Internet), aspectos culturais em pesquisa acadêmica: um estudo entre professores e alunos da FEA-USP. São Paulo : ENAMPAD, 1997. p. 187-102.

CHAGAS, J.; ARRUDA, S.; BLATTMANN, U. Interação do usuário na busca de informação. In: SEMINÁRIO DE BIBLIOTECAS UNIVERSITÁRIAS, 11, 2000, Florianópolis. Anais.... Florianópolis : UFSC, 2000.

COLE, C. Intelligent information retrieval: diagnosing information need. Part I. the theoretical framework for developing an intelligent IR tool. Inf. Proces. Manag., v .34, n. 6, p. 709-720, 1998.

COOPER, $\mathrm{R}$ et al. Library users-needs and expectations: library trends. Urbana, Summer 1998.

CUENCA, A. M. B.; MORAES, C.; FONTES, C. de A. Uso da internet por usuários de bibliotecas acadêmicas. In: SEMINÁRIO DE BIBLIOTECAS UNIVERSITÁRIAS, 11, 2000, Florianópolis. Anais... Florianópolis : UFSC, 2000.

CUTRIGHT, P. .J.; GIRRARD, K. Applying innovative technology for the needs of the distant LEA. Libr. Hi Tech, v. 11, n. 4, p. 67-74, 1993.

DERVIN, B.; NILAN, M. Workshop design de bibliotecas virtuais centrado na usuário: a abordagem do sense-making para estudo de necessidades e comportamento de busca e uso das informações. São Paulo : USP, 1997. 


\section{Eliane Maria Stuart Garcez / Gregório J. Varvakis Rados}

DRUMOND, F. B. Ouvindo o cliente para o planejamento do produto. In: CHENG, L. C. QFD: planejamento da qualidade. Belo Horizonte : UFMG, 1995.

DUDZIAK, E. A.; GABRIEL, M. .A.; VILLELA, M. C. A educação de usuários de bibliotecas universitárias frente à sociedade do conhecimento e sua inserção nos novos paradigmas educacionais. In: SEMINÁRIO DE BIBLIOTECAS UNIVERSITÁRIAS, 11, 2000, Florianópolis. Anais.... Florianópolis : UFSC, 2000.

ERAZO, E.; DERLIN, R. L. Distance learning and libraries in the cyberspace age. In: PROOCEDINGS OF 1995 CONFERENCE OF THE COUNCIL FOR HIGHER EDUCATION COMPUTING SERVICES, New Mexico, 1995. New Mexico, [S. n.], 1995. 7 p.

FAIBISOFF, S. G.; ELY, D. P. Information needs. Inf. Rep. Bibliog., v. 5, n. 5, p. 2-16, 1976.

FERREIRA, S. M. S. P. Redes eletrônicas e necessidades de informação: a abordagem do sense-making para estudo de comportamento de usuários do Instituto de Física da USP. São Paulo, 1995. 165 f. Tese (Doutorado em Comunicação e Artes) - Escola de Comunicação e Artes da Universidade de São Paulo, São Paulo. 1995.

FIGUEIREDO, N.M. de. Estudo de uso e usuários da informação. Brasília : IBICT, 1994. $154 \mathrm{p}$.

GIANESI, I. G. N.; CORRÊA, H. L. Administração estratégica de serviços: operações para a satisfação do cliente. São Paulo : Atlas, 1994. $233 \mathrm{p}$.

GUINCHAT, C.; MENOU, M. Introdução geral às ciências e técnicas da informação e documentação. 2. ed. rev. e aum. Brasília, 1994. 540 p.

HERON, P.; DUGAN, R. E. Information police distance education: provider and victim libraries. J. Acad. Librarinship, v. 23, n. 4, p. 315 318, Jul. 1997.

HyPÓlito, A.; ROSetto, M.; COUTO, M. L. de M. do. Identificação e evolução de demanda de informação de usuários, via correio eletrônico do departamento técnico do sistema integrado de bibliotecas da USP. In: SEMINÁRIO DE BIBLIOTECAS UNIVERSITÁRIAS, 11, 2000, Florianópolis. Anais... Florianópolis : UFSC, 2000

JANGANNATHAN, N. Library and information services for distance learners. Res. Shar. Inf. Networks, v. 11, n. 1-2, p. 159-170, 1996.

KOTLER, P.; AMSTRONG, G. Princípios de marketing. 5. ed. Rio de Janeiro : Prentice Hall, 1993. 477 p.

KUHLTHAU, C. C. Seeking meaning: a process approach to library and information services. 2. ed. Norwood: Ablex, 1994. 199 p.

LANCASTER, F. W. Assessment of technical information requirements of users. In: REES, A. (Ed.). Contemporary problems in technicals library and information centers: management: a state of the art. Washington : ASSIS, 1974.

. Information retrievel systems: characteristics, testing and evaluations. 2. ed. New York : Intercience, 1979.

LINGUANOTTO, A. R .J et al. Indicadores de qualidade para o serviço de referência e informação: uma proposta de aplicação às bibliotecas do SIB/USP. In: SEMINÁRIO DE BIBLIOTECAS

UNIVERSITÁRIAS, 11, 2000, Florianópolis. Anais.... Florianópolis : UFSC, 2000.

MACAULEY, P. Distance education research students and their library use. Aust. Acad. Res. Libr., v. 28, p. 188-197, Sept. 1997.

MACDOUGALL, J.; BRITTAIN, J. M. Library and information science education in the United Kingdon. ARIST, v. 28, p. 361-390, 1993.
MOSTAFA, S. P. Estudos de usuários ou suco de laranja na biblioteca: notas ordinárias. Cadernos de Biblioteconomia, Recife, n. 8, p. 7-16, jun. 1984.

OBERHOFER, C. A. Acessibilidade de documentos e satisfação da demanda: um modelo de avaliação. Rev. Bibliotecon., Brasília, v. 11, n. 1, p. 19-33, jan./jun. 1983.

OLIVEIRA JÚNIOR, J. Aspectos da qualidade em serviços. Trib. Livre, n. 28 , p. $45-54$, set. 1994 .

PAIM, I.; NEHMY, R. M Q.; GUIMARÃES, C. G. Problematização do conceito qualidade da informação. Perpect. Ci. Inf., Belo Horizonte, v. 1, n. 1, p. 111-119, jan./jun. 1996.

PITKOW, J. E.; KEHOE, C. M. Emerging trends in the www users population. Commun. ACM, v. 30, n. 6, June 1996.

RAMOS, M. E. M. (Org.). Tecnologia e novas formas de gestão em bibliotecas universitárias. Ponta Grossa : UEPG, 1999. 257 p.

ROBERTS, D.E. H. An analysis of the request and reservation service of Nottighmshire County Library. J. Librariansh., v. 5, n. 1, p. 9-27, Jan. 1973

RODRIGUES, R. S. Modelo de avaliação para cursos no ensino a distância: estrutura, aplicação e avaliação. 1998.. Dissertação (Mestrado em Engenharia de Produção) - Universidade Federal de Santa Catarina, Florianópolis, Florianópolis, 1998.

RUDIO, F. V. Introdução ao projeto de pesquisa científica. 25. ed. Petropolis : Vozes, 1999. 144 p.

RUSCH-FEJA, D. Digital libraries: informatioform de zunkunft fur die informationsversorgung und informationsbereitstellung? Disponível em: $<$ http://www.b-i-t-online.de/archiv/1999-02/fachbeit/rushfeja/ artikel.htm> Acesso em: 19 jun. 2000.

SADI, B. S. C.; REIS, M.G. C. Produtos e serviços de informação disponíveis em bibliotecas acadêmicas: estudo para apoio aos programas de educação a distância. In: SEMINÁRIO DE BIBLIOTECAS

UNIVERSITÁRIAS, 11, 2000, Florianópolis. Anais.... Florianópolis : UFSC, 2000.

SALOMON, D. V. Como fazer uma monografia: elementos de metodologia do trabalho científico. 5. ed. Belo Horizonte : Interlivros, 1977. $317 \mathrm{p}$.

SHERA, J. Epistemologia social, semântica geral e biblioteconomia. Ciência da Informação, Brasília, v. 6, n. 1, p. 9-12, 1977.

SHOUSE, D. L. Library needs of rural distance education students (at East Carolina University). In: OFF-CAMPUS LIBRARY SERVICES CONFERENCE, 7, San Diego, 1995. Reports... San Diego [S. n.], 1995, p. 355-62.

SOUSA, C. G. de. A biblioteca universitária e a pesquisa científica na Universidade Federal de Santa Catarina. Florianópolis, 1990. 144 f. Dissertação (Mestrado em Administração) - Universidade Federal de Santa Catarina. Florianópolis, 1990.

TAYLOR, R. S. Question-negociation and information seeking in libraries. Coll. Res. Libr., v. 29, p. 178-194, 1968.

WIELHORSKI, K. Teaching a remote users how to use electronic information resources. Pub. Access Comp. Syst. Rev., v. 5, n. 4, p. 5-20, 1994.

WOOD, W. H.; AGOGINO, A. M. Engineering course ware content and delivery: the needs infrasructure for distance independent education. J. Amer. Soc. Inf. Sci., v. 47, p. 863-869, Nov. 1996.

ZHOU, Y. From smart guesser to smart navigator: changes in collection development for research libraries in a network environment. Libr. Trends, v. 42, n. 4, p. 648-60, Spring, 1994. 


\section{APÊNDICE 1- Questionário}

Este questionário será utilizado como teste em uma dissertação, com o fim de detectar quais bens e serviços são necessários para a criação de um modelo de biblioteca virtual, para apoio do ensino e das pesquisas nos cursos de ensino a distância em Engenharia de Produção (EPS). Portanto, a sua colaboração é de grande importância no preenchimento do mesmo.

1. Qual sua categoria?

[1] mestrando [2] professor

2. Qual seu propósito na utilização de uma biblioteca?

[1] atualização do conhecimento

[3] monografia, dissertação, tese
[2] artigos técnicos científicos

[4] Se outros: quais?

As perguntas de $\mathrm{n}^{\mathrm{o}} 3$ a n⿳o 8 poderão ser de múltipla escolha, devendo ser respondidas em ordem de prioridade.

3. Quais os meios que você utiliza para recuperar informações?

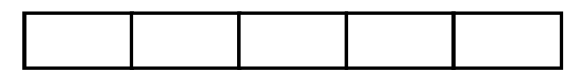

[1] bases de dados na Internet [2] bibliotecas

[3] base de dados em CD-rom

[4] contatos interpessoais (colégios invisíveis)

[5] Se outros: quais?

4. Em se tratando de bibliotecas, quais costuma pesquisar?

[1] em nível local (indique o nome e a cidade)

[2] virtualmente (indique o nome e o endereço eletrônico, se possível)

5. Quais os instrumentos de busca mais utilizados em sua pesquisa?

\begin{tabular}{|l|l|l|l|}
\hline & & & \\
\hline
\end{tabular}

[1] lycos

[2] yahoo

[3] alta vista

[4] metacrawler

[5] Se outros: quais?

6. Quais bens informacionais costuma pesquisar?

[1] artigos de periódicos (papers)

[3] apostilas de aula

[5] monografias, dissertações, teses

[7] Se outros: quais?

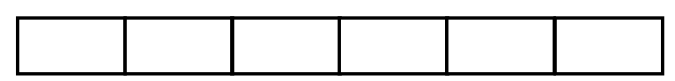

[2] anais de congressos, seminários, simpósios etc.

[4] livros

[6] fontes eletrônicas

7. Como gostaria de adquirir as informações acessadas? Através de:

[1] empréstimo domiciliar

[3] donwload
[2] comutação bibliográfica

[4] Se outros: quais?

8. Considerando suas atividades de pesquisa, como se comunica com outros pesquisadores?

Através:

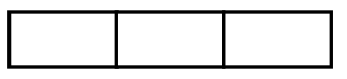

[1] contato pessoal

[5] fóruns eletrônicos
[2] telefone [3] fax

[6] listas de discussões
[4] correios eletrônicos

[7] Se outros: quais? 


\section{Eliane Maria Stuart Garcez / Gregório J. Varvakis Rados}

9. Como participa dos fóruns eletrônicos?

[1] ouvinte [2] ativo participante (apresenta problemas e busca soluções)

[3] conduz debates [4] Se outros: quais?

10.Quais listas de discussões costuma assinar?

11. Qual a freqüência utilizada na busca de informações?

[1] uma vez por semana

[2] duas ou três vezes por semana

[3] menos de uma vez por mês [4] todos os dias

[5] quase todos os dias

12. Qual sua área de concentração?

[1] mídia e conhecimento

[2] gestão de qualidade e produtividade

[4] transporte e logística

[5] gestão de design do produto

[7] inteligência aplicada

[8] gestão de qualidade ambiental

[3] ergonomia

[6] gestão de negócios

13. Qual(is) o(s) tema(s) de seu interesse?

14. Qual o tempo tolerável para obtenção de um documento, quando remetido via e-mail?

[1] menos de 3 dias

[2] entre 4 e 7 dias

[3] no máximo até 10 dias

[4] + de 10 dias

15. Qual o tempo tolerável para obtenção de um documento, quando remetido via correio?

[1] menos de 7 dias

[3] no máximo 15 dias

[2] entre 7 e 10 dias

$[4]+$ de 15 dias

16. Você já foi instruído no uso de bibliotecas virtuais?
[1] $\operatorname{sim}$
[2] não

17. Você acha importante este treinamento?
[1] $\operatorname{sim}$
[2] não

18. Como você gostaria que este treinamento ocorresse?

[1] tutoriais interativos

[2] guias eletrônicos on-line

[3] na primeira aula do curso (virtualmente), acompanhado de apostila impressa

[4] se outros, quais? 